\title{
Efficacy of Horticultural Activity in Elderly People with Dementia: A Pilot Study on the Influence on Vitality and Cognitive Function
}

\section{Junko Masuya $^{1^{*}}$ and Kikuko Ota ${ }^{2}$}

${ }^{1}$ Faculty of Health Sciences, Tokyo Metropolitan University, 7-2-10 Higashi-Ogu, Arakawa-ku, Tokyo, 116-8551, Japan

${ }^{2}$ Faculty of Nursing and Medical Care, Keio University, 4111 Endo, Fujisawa-shi, Kanagawa, 252-0816, Japan

\begin{abstract}
Objective: The purpose of this pilot study was to examine the effects of an intervention of the horticultural activities program in elderly people with mild to moderate dementia.

Methods: The study design was a before-after study. The subjects were 11 elderly people with dementia. The horticultural activities program was developed to support mental, behavioral, social, and cognitive aspects of well-being in elderly patients. The program was conducted once a week for a total of six weeks. Vitality Index (VI) and Mini-Mental State Examination (MMSE) were used to determine the effects of the horticultural activities program.

Results: The results showed that VI and MMSE scores significantly improved immediately after intervention compared with those at baseline. In addition, the scores significantly decreased after 1 month of intervention compared with those immediately after the intervention.

Conclusion: In this study, VI and MMSE scores of elderly people with mild to moderate dementia improved after participation in the horticultural activities program. However, as the number of subjects was small in the present study, further studies are required to fully elucidate the effects of a horticultural activities program.
\end{abstract}

\section{Introduction}

In Japan, the elderly population continues to increase and is expected to reach a considerable proportion of the overall population [1]. Recent reports indicate that the number of elderly people with dementia has rapidly increased with an increase in the aging population in all developed countries. In Japan particularly, by the year 2030, the proportion of the elderly people with dementia is estimated to reach approximately 3 million, almost three times the present number [2].

Although medications are available to slow the progression of dementia, none offer curative effects. Thus, non-pharmacological therapies play important roles in the general mental well-being of these people [3]. Non- pharmacological therapies, such as music, reminiscence, art, and reality orientation therapies, have been shown to effectively improve the quality of life (QOL) and prevent disability among elderly people. Among these therapies, horticultural activities encourage interaction between people and plants [4].

Over the past few decades, a number of relevant reports and studies have described the importance of horticultural activities for elderly people with dementia and reported positive results, including improvements in psychological [5], physical [6], social [7], and cognitive [8] aspects of individual functioning.

Based on these studies, horticultural activities appear to be promising treatment modalities for elderly people with dementia. However, it is difficult to generalize the results of these studies due to methodological weaknesses. First, the selection of the study subjects is questionable because the diagnostic criteria of dementia remain unclear. Second, the intervention methods varied among previous studies.

Nonetheless, the horticultural activities program for elderly people with mild to moderate dementia have been proposed $[9,10]$ based on the theory of personhood in dementia, as reported by Kitwood [11], which emphasizes the need for caregivers to adopt individualized methods in approaches for dementia care.

The purpose of this pilot study was to examine the effects of an intervention of the horticultural activities program in elderly people with mild to moderate dementia.

\section{Methods}

The study design was a before-after study. The flow of the implementation method is shown in Figure 1. During the intervention period, the subjects cared for plants daily, in addition to participating in the horticultural activities program. The sessions lasted 30-40 min once a week for six consecutive weeks. During the nonintervention period, the horticultural activities program and care of plants was suspended. During the study period, the subjects received usual dementia care. The month long nonintervention period was imposed based on the findings of a previous study, which reported that the effects of horticultural activities completely disappeared after four weeks [12].

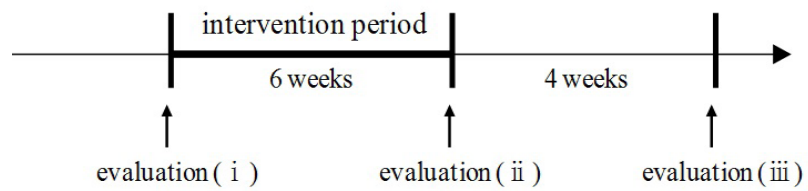

Figure 1: Design (flow of implementation method) To evaluate the effects of the horticultural activities program, the Vitality Index and MMSE scores were assessed three times: (i) Before the intervention period, (ii) immediately after intervention, and (iii) one month after intervention.

"Corresponding Author: Dr. Junko Masuya, Faculty of Health Sciences, Tokyo Metropolitan University, 7-2-10 Higashi-Ogu, Arakawa-ku, Tokyo,116-8551, Japan; E-mail:masuya@tmu.ac.jp

Citation: Masuya J, Ota K (2014) Efficacy of Horticultural Activity in Elderly People with Dementia: A Pilot Study on the Influence on Vitality and Cognitive Function. Int J Nurs Clin Pract 1: 101. doi: http//dx.doi.org/10.15344/2394 4978/2014/101

Copyright: (c) 2014 Masuya et al. This is an open-access article distributed under the terms of the Creative Commons Attribution License, which permits unrestricted use, distribution, and reproduction in any medium, provided the original author and source are credited. 
Citation: Masuya J, Ota K (2014) Efficacy of Horticultural Activity in Elderly People with Dementia: A Pilot Study on the Influence on Vitality and Cognitive Function. Int J Nurs Clin Pract 1: 101. doi: http://dx.doi.org/10.15344/2394-4978/2014/101

\section{Subjects}

The subjects $(\mathrm{n}=11)$ were elderly people with dementia residing in a long-term care facility. The inclusion criteria of this study were: (i) age of 65 years or older; (ii) diagnosis of dementia from a physician based on DSM- $\square$-TR; (iii) Clinical Dementia Rating (CDR) [13] score of 1 or 2; (iv) no speech or vision disorders, and (v) no participation in other research studies. There were 15 eligible patients who met the inclusion requirements of this study. The researchers then fully explained the study objectives, study methods, and freedom of choice of participation in the study to the potential participants. After interviewing each patient and their families, 11 submitted informed consent.

Subject data, including favorite plants and experiences with plants and plant care, were obtained in advance from each subject and their families. Nurses assessed the physical and mental health of the subjects to determine whether they were able to attend the horticultural activities program and confirm their willingness to participate.

Mini-Mental State Examination (MMSE), which is scored on a scale of 0 to 30 points [14], was used before the study for baseline evaluation. The MMSE score of each subject was less than 23 points at baseline. The distribution of subjects is shown in Table 1. Of the 11 subjects ( 7 males and 13 females; median age, 88 years; age range, 72-93 years) included for the analysis, two were diagnosed with Alzheimer's disease and nine with vascular dementia. Five patients had a CDR of 1 (mild) and six had a CDR of 2 (moderate).

\begin{tabular}{|c|c|c|}
\hline Variables & Response Category & $\mathrm{n}(\%)$ \\
\hline Gender & Female & $9(82 \%)$ \\
\hline & Male & $2(18 \%)$ \\
\hline Age(median) & & 88 \\
\hline AD & & $2(18 \%)$ \\
\hline VaD & & $9(82 \%)$ \\
\hline CDR1(mild) & & $5(55 \%)$ \\
\hline CDR2(moderate) & & $6(45 \%)$ \\
\hline Gardening experience & & $6(45 \%)$ \\
\hline & A lot of experience & $5(55 \%)$ \\
\hline
\end{tabular}

Table 1: Distribution of subjects.

$\mathrm{AD}$, Alzheimer's disease; $\mathrm{VD}$, vascular dementia; $\mathrm{CDR}$, clinical dementia rating

\section{Intervention methods}

The horticultural activities program was designed to support mental, behavioral, social, and cognitive aspects of the well-being in elderly people with dementia. The subjects were divided into groups of three or four. During every activity, a specialist (author), care worker (facility staff), and research collaborator supported the groups. The specialist had several years of experience in caring for elderly people with dementia as a nurse and was trained in techniques of horticultural activities. The specialist performed the role of a group leader. During the session, the facility staff was assigned to observe the behavior of each subject. The research collaborator evaluated the behavior of each subject. The basic session flow and schedule are shown in Table 2. The seed or plant material used had the following properties: "good germinativeness," "easy to grow," "suitable to the season," "caused sensory stimulation" (seeds and plants of various sizes, form, color, and smell), and "well-known."

\begin{tabular}{|c|c|c|}
\hline Time & \multicolumn{2}{|l|}{ Content } \\
\hline $1-2 \mathrm{~min}$ & \multicolumn{2}{|c|}{ Welcome participants to activities } \\
\hline $5 \mathrm{~min}$ & \multicolumn{2}{|l|}{ Introductions } \\
\hline $5 \mathrm{~min}$ & \multicolumn{2}{|c|}{$\begin{array}{l}\text { Taking care of plant \& observations, sensory } \\
\text { stimulation }\end{array}$} \\
\hline & \multicolumn{2}{|c|}{$\begin{array}{l}\text { Start vegetables from seed that germinate easily } \\
\text { and are easy to grow }\end{array}$} \\
\hline $15-20 \mathrm{~min}$ & \multicolumn{2}{|c|}{$\begin{array}{l}\text { Transplant flowers into individual pots, puring } \\
\text { and harvesting of plants }\end{array}$} \\
\hline & \multicolumn{2}{|l|}{ Closing ceremony } \\
\hline $5 \mathrm{~min}$ & \multicolumn{2}{|c|}{ Purning and harvesting of plants } \\
\hline $1-2 \mathrm{~min}$ & \multicolumn{2}{|l|}{ Closing ceremony } \\
\hline \multirow{2}{*}{ Session } & \multicolumn{2}{|c|}{ Schedule } \\
\hline & Work to arouse memories & New work \\
\hline Week 1 & & Seeding of redish \\
\hline Week 2 & Thinning of radish & $\begin{array}{l}\text { Seeding of baby } \\
\text { leaf }\end{array}$ \\
\hline Week 3 & Fertilizer to the redish & $\begin{array}{l}\text { Transplant } \\
\text { chrysanthemum }\end{array}$ \\
\hline Week 4 & Thinning of baby leaf & $\begin{array}{l}\text { Seeding white } \\
\text { radish sprouts }\end{array}$ \\
\hline Week 5 & \multicolumn{2}{|c|}{ Harvesting of white redish sprouts } \\
\hline Week 6 & \multicolumn{2}{|c|}{ Harvesting of redish and baby leaf } \\
\hline
\end{tabular}

Table 2: Design of the horticultural activities program.

\section{Evaluation methods}

In this study, the vitality and cognitive functions of the subjects were evaluated. Vitality was evaluated using Vitality Index (VI) [15] and cognitive function was evaluated using MMSE [14]. A total of three assessments were performed. MMSE scores were evaluated by the researcher. In addition, the care worker in the unit, who knew the subjects, also evaluated the behavior of each participant based on VI. Before the intervention period, the author conducted a study session to explain the evaluation methods to the facility staff to ensure the reliability of assessment.

\section{Statistical analyses}

We tested the statistical significance of all alignment results using the Friedman test and Scheffe multiple comparison test. ASPSS 17.0 statistical software was used for data analysis. A probability ( $\mathrm{p}$ ) value of $<0.05$ was considered statistically significant.

\section{Results}

The participation rate for the horticultural activities program was $100 \%$ because no patient dropped out during the study period. The results of VI and MMSE scores are shown in Table 3, and the results of multiple comparisons between these scores are shown in Table 4 .

The VI total scores showed significant improvements immediately after the intervention (median, 9.0; range, 7-10) compared with those at baseline (median, 8.0; range, 5-9; $p<0.01$ ). The VI scores 
Citation: Masuya J, Ota K (2014) Efficacy of Horticultural Activity in Elderly People with Dementia: A Pilot Study on the Influence on Vitality and Cognitive Function. Int J Nurs Clin Pract 1: 101. doi: http://dx.doi.org/10.15344/2394-4978/2014/101

Page 3 of 4

\begin{tabular}{|c|c|c|c|c|c|c|}
\hline & \multicolumn{3}{|c|}{ Time } & & & \\
\hline & Before & Immediate & After 1 month & & & \\
\hline Evaluation & Median (range) & Median(range) & Median(range) & df & $\varkappa^{2}$ & p-value \\
\hline Vitality Index(Total) & $8.0(5-9)$ & $9.0(7-10)$ & $8.0(6-10)$ & 2 & $18.727^{\star \star}$ & 0.001 \\
\hline 1. Waking pattern & $2.0(1-2)$ & $2.0(1-2)$ & $2.0(1-2)$ & 2 & 0.000 & 1.000 \\
\hline 2. Communication & $1.0(0-2)$ & $2.0(1-2)$ & $1.0(0-2)$ & 2 & $12.000^{* *}$ & 0.011 \\
\hline 3. Feeding & $2.0(1-2)$ & $2.0(1-2)$ & $2.0(1-2)$ & 2 & 0.000 & 1.000 \\
\hline 4. On and off toilet & $2.0(1-2)$ & $2.0(1-2)$ & $2.0(1-2)$ & 2 & 0.000 & 1.000 \\
\hline 5. Rehabiliation and other activities & $1.0(0-1)$ & $2.0(1-2)$ & $1.0(0-2)$ & 2 & $16.222^{\star *}$ & 0.021 \\
\hline MMSE(Total) & $17.0(11-22)$ & $19.0(14-23)$ & $17.0(12-23)$ & 2 & $12.398^{\star *}$ & 0.002 \\
\hline 1. Orientation & $4.0(3-6)$ & $5.0(4-6)$ & $4.0(3-6)$ & 2 & $10.333^{\star *}$ & 0.005 \\
\hline 2. Registration & $3.0(2-3)$ & $3.0(2-3)$ & $3.0(2-3)$ & 2 & 2.000 & 0.368 \\
\hline 3. Attention and Claculation & $3.0(2-4)$ & $3.0(2-4)$ & $3.0(2-4)$ & 2 & 5.429 & 0.066 \\
\hline 4. Recall & $2.0(1-3)$ & $2.0(1-3)$ & $2.0(1-3)$ & 2 & 4.667 & 0.097 \\
\hline 5. Language & $6.0(3-7)$ & $6.0(3-7)$ & $6.0(3-7)$ & 2 & 1.727 & 0.422 \\
\hline 6. Visual construction & $1.0(0-1)$ & $1.0(0-1)$ & $1.0(0-1)$ & 2 & 1.000 & 0.607 \\
\hline
\end{tabular}

Table 3: Change in Vitality Index and MMSE scores.

${ }^{* *} \mathrm{p}<0.01$, Friedman test

\begin{tabular}{|l|l|l|l|l|}
\hline \multicolumn{5}{|c|}{ Comparsion of the time } \\
\hline Evaluation & $\begin{array}{l}\text { Before } \\
\text { Immediate } \\
\text { Median } \\
\text { (range) }\end{array}$ & p-value & $\begin{array}{l}\text { Immediate } \\
\text { After 1 month } \\
\text { Median } \\
\text { (range) }\end{array}$ & $p$-value \\
\hline $\begin{array}{l}\text { Vitality Index } \\
\text { (total) }\end{array}$ & $\begin{array}{l}8.0(5-9) \\
9.0(7-10)\end{array}$ & $0.001^{* *}$ & $\begin{array}{l}9.0(7-10) \\
8.0(6-10)\end{array}$ & $0.012^{*}$ \\
\hline Communication & $\begin{array}{l}1.0(0-2) \\
2.0(1-2)\end{array}$ & $0.023^{*}$ & $\begin{array}{l}2.0(1-2) \\
1.0(0-2)\end{array}$ & $0.042^{*}$ \\
\hline $\begin{array}{l}\text { Rehabiliation \& } \\
\text { other activities }\end{array}$ & $\begin{array}{l}1.0(0-2) \\
2.0(1-2)\end{array}$ & $0.067^{*}$ & $\begin{array}{l}2.0(1-2) \\
1.0(0-2)\end{array}$ & $0.011^{*}$ \\
\hline MMSE (Total) & $\begin{array}{l}17.0(11-22) \\
19.0(14-23)\end{array}$ & $0.003^{* *}$ & $\begin{array}{l}19.0(14-23) \\
17.0(11-22)\end{array}$ & $0.037^{*}$ \\
\hline Orientation & $\begin{array}{l}4.0(3-6) \\
5.0(4-6)\end{array}$ & $0.011^{*}$ & $\begin{array}{l}5.0(4-6) \\
4.0(3-6)\end{array}$ & $0.043^{*}$ \\
\hline
\end{tabular}

Table 4: Multiple Comparisons of Vitality Index and MMSE scores.

${ }^{* *} p<0.01,{ }^{*} p<0.05$; Scheffé multiple comparison test

significantly decreased after one month of participation in the intervention program (median, 8.0; range, 6-10) compared with those immediately after the intervention $(p<0.01)$. There were significant improvements in the total MMSE scores immediately after the intervention (median, 19.0; range, 14-23) compared with those before participation (median, 17.0; range, 11-22; $p<0.01$ ). Furthermore, the MMSE scores significantly decreased 1 month after the intervention (median, 17.0; range, 12-23) compared with those immediately after the intervention $(p<0.05)$.

\section{Discussion}

The results of this study indicate the effectiveness of the horticultural activities program to improve short-term vitality and cognitive function of elderly people with dementia. The total VI and MMSE scores significantly improved immediately after the intervention.

There was a significant improvement in the VI subscales of "Rehabilitation and other activities" and "Communication" immediately after the last session of intervention. To the best of our knowledge, no previous study has reported a significant improvement in VI after horticultural activities in elderly people with dementia. In a 3-month once weekly intervention (total 12 sessions), Toyoda et al. [16] reported an improvement in the "Rehabilitation and other activities" subscale of VI. However, in the present study, a total of six sessions of the horticultural activities program were administered over a 1.5 -month period. The term of the present study was shorter than that previously reported. The results of the present study, which indicated the efficacy of a short term horticultural activities program on vitality, are a new finding.

The significant improvement in the VI subscales of "Communication" and "Rehabilitation and other activities" scores in the present study after participation in the horticultural activities program for six weeks was attributed to the fact that subjects were able to take care of plants and share their experiences with others.

The activities of elderly people with dementia and their communication with others tend to decrease when living in a facility, resulting in decreased cognitive function. In this context, improvement in the VI subscales of "Communication" and "Rehabilitation and other activities" scores in the present study is of great significance.

In this study, the MMSE scores significantly improved immediately after the intervention compared with those at baseline. There was a significant improvement in the MMSE subscale "Orientation" immediately after the last intervention session. In a previous 2-month study of horticultural activities, the MMSE scores significantly improved after intervention compared with those at baseline [17]. In the present study, the horticultural activities program was administered for 1.5 months. Hence, the term was shorter than that in the previous study. The results of the present study, which indicate the efficacy of a short-term horticultural activities program on MMSE, 
Citation: Masuya J, Ota K (2014) Efficacy of Horticultural Activity in Elderly People with Dementia: A Pilot Study on the Influence on Vitality and Cognitive Function. Int J Nurs Clin Pract 1: 101. doi: http://dx.doi.org/10.15344/2394-4978/2014/101

constitute a new observation. "Work to arouse memories" was administered to confirm the day's date and to introduce reality orientation. In addition, the subjects continuously provided daily care to the plants. By these methods, reality orientation was reinforced and significant improvements were observed in the MMSE subscale "Orientation" score. Considering that with advancing dementia patients are not able to recognize the surrounding environment, the improvement in the MMSE subscale "Orientation" score in the present study is of great significance.

The purpose of this pilot study was to examine the effects of an intervention of the horticultural activities program in elderly people with mild to moderate dementia. The results indicate the efficacy of the horticultural activities program on the short-term improvement vitality and cognitive function. In contrast, the horticultural activities program had no effect on long-term improvements to vitality and cognitive function. The results of the present study are consistent with those reported by Sugihara et al. [12]. who concluded that a time-limited program consisting of horticultural activities may only allow for short-term improvement but did not promote long-term improvements. Thus, to maintain this effect, it may be necessary to provide a sustained intervention.

The major limitations of the present pilot study were the small number of subjects and the nonrandomized nature of the trial Therefore, further investigations and randomized controlled trials with a greater number of subjects are necessary to confirm the effects of a long-term horticultural activities program for elderly people with dementia. In addition, there were no differences in effects on the intervention based on the underlying disease.

\section{Conclusion}

The purpose of this pilot study was to examine the effects of an intervention of the horticultural activities program in elderly people with mild to moderate dementia. The VI and MMSE scores showed significant improvements immediately after the intervention period compared with those at baseline. The results indicate the efficacy of the horticultural activities program to improve short-term vitality and cognitive function. These results suggest that this program may be an effective treatment modality to improve vitality and cognitive function in this people population.

\section{Competing Interests}

The authors declare that they have no competing interests.

\section{Funding}

This research was supported by a grant from the 2011 Keio University doctoral student support program.

\section{Acknowledegements}

The authors are grateful to all participants and the care staff of the facility.

\section{References}

1. The society of gerontological care, eds. Aiming at the establishment of care to support the elderly people's dignity in 2015. Tokyo: Houken, 2004

2. Shiba $M$, Shimogaito J, Kose A, Fujiuchi $S$, Nishiyama $H$, et al (1999) Prevalence of dementia in the rural village of hanazono-mura. Neuroepidemiology 18: 32-36.
3. Kaplan R (1973) Some psychological benefits of gardening. Environ Behavior 5: 145-162.

4. Mills MS (1997) Narrative identity and dementia: A study of emotional and narrative in older people with dementia. Aging Society 17: 673-698.

5. Willcox RT, Mattson RH ((1979)) Horticultural therapy maintains lifesatisfaction of geriatrics. Great Plains J Hort Therapy 1: 8-12.

6. Barinicle T, Midden KS (2003) The effects of a horticulture activity program on the psychological well-being of older people in a long-term care facility. Hort Technology 5: 94-103.

7. Hill CO, Relf PD (1983) Gardening as an outdoor activity in geriatric institutions. Activities, Adaptation \& Aging 3: 47-53.

8. Relf D, Dor C (1995) Horticulture: Meeting the needs of special populations. Hort Technology 5: 94-103.

9. Masuya J (2011) Development of horticultural activities program to change behavior for the elderly with dementia. Jan J Academy of Gerontological Nursing 15: 54-63.

10. Masuya J (2012) Analysis of care method which matched individual characteristics of the elderly with mild to moderate dementia in horticultural activities. Jpn Society for Dementia Care 11: 576-589.

11. Kitwood R, Bredin K (1992) Towards a theory of dementia care: Personhood and well-being. Aging and Society 12: 269-287.

12. Sugihara S, Hiroshi A, Sugimoto M, Takeda S, Ikeda N, et al. (2006) The psychological, cognitive and immunological effects of horticultural therapy on the elderly living in a nursing home. Jpn J Geriatric Psychiatry 17: 967975.

13. Morris J (1993) The Clinical Dementia Rating (CDR): current version and scoring rules. Neurology 43: 2412-2414.

14. Folstein MF, Folstein SE, Mchugh PR (1975) "Mini-mental state". A practical method for grading the cognitive state of patients for the clinician. J Psychiatr Res 12: 189-198.

15. Toba K, Nakai R., Akishita M, lijima S, Nishinaga M, et al. (2003) Vitality Index as useful tool to assess elderly with dementia. Geriatrics and Gerontology International 2: 23-29.

16. Toyoda M, Makimura S, Amano T, et al. (2010) The effects of horticultural therapy on the aged in day service. Jpn Society for Dementia Care 9: 9-17.

17. Yasukawa M, Chiba S, Ito $Y$ (2005) A study on the effectiveness of horticultural therapy for the elderly with dementia. Jpn society of peopleplant relationships 5: 20-21. 